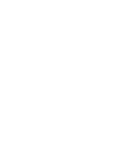
ANNUAL Further
REVIEWS

Click here for quick links to Annual Reviews content online, including:

- Other articles in this volume

- Top cited articles

- Top downloaded articles

- Our comprehensive search

\title{
Advances in the Study of Coevolution Between Avian Brood Parasites and Their Hosts
}

\author{
William E. Feeney, ${ }^{1,2}$ Justin A. Welbergen, ${ }^{3}$ \\ and Naomi E. Langmore ${ }^{1}$
}

\footnotetext{
${ }^{1}$ Research School of Biology, The Australian National University, Canberra ACT 0200, Australia; email: william.e.feeney@gmail.com, naomi.langmore@anu.edu.au

${ }^{2}$ Evolutionary Ecology Group, Department of Zoology, University of Cambridge, Cambridge CB2 3EJ, United Kingdom

${ }^{3}$ Hawkesbury Institute for the Environment, The University of Western Sydney, Penrith NSW 2751, Australia; email: j.welbergen@uws.edu.au
}

Annu. Rev. Ecol. Evol. Syst. 2014. 45:227-46

First published online as a Review in Advance on September 25, 2014

The Annual Review of Ecology, Evolution, and Systematics is online at ecolsys.annualreviews.org

This article's doi:

10.1146/annurev-ecolsys-120213-091603

Copyright (c) 2014 by Annual Reviews. All rights reserved

\section{Keywords}

arms race, brood parasitism, evolution, parasitism, species interactions

\section{Abstract}

The interactions between avian obligate interspecific brood parasites and their hosts provide tractable systems for studying coevolutionary processes in nature. This review highlights recent advances in understanding coevolution in these systems. First, we discuss the evolution and phylogenetic history of avian brood parasitism. Next, we examine coevolved adaptations and counteradaptations in brood parasites and hosts at all stages of the host nesting cycle: those that precede laying of the parasitic egg and those at the egg, chick, and fledgling stages. We then consider the factors that affect the evolution of offense and defense portfolios (the suites of adaptations and counteradaptations across the nesting cycle), and the outcomes of coevolutionary interactions between brood parasites and hosts. Ongoing efforts to document the diversity of host defenses and parasite offenses will facilitate understanding of coevolutionary processes and the ecological and evolutionary consequences of species interactions in the natural world. 


\section{INTRODUCTION}

The importance of species interactions as drivers of natural selection was recognized by Charles Darwin in On the Origin of Species: "As natural selection acts by competition, it adapts the inhabitants of each country only in relation to the degree of perfection of their associates" (Darwin 1859, p. 472). Consequently, the intimate nature of coevolutionary relationships, in which two or more species undergo reciprocal heritable change through their interactions with one another, led to their use as tractable models for studying the evolutionary process itself (Thompson 1994).

Coevolution can be studied from a theoretical perspective, in experimental laboratory conditions, or in the natural world (Thompson 1994). In the natural world, the interactions between brood parasitic birds and their hosts have been the subject of enduring fascination and study, spanning from Aristotle (fourth century BC; Hett 1936, Davies \& Brooke 1988) and Charles Darwin (1859) to the present (Rothstein 1990, Davies 2000).

Brood parasitism is a breeding strategy in which a parasite manipulates a host to raise its offspring. It is phylogenetically widespread and has been identified in arthropods, fishes, and birds (Feeney et al. 2012). Brood parasites may exploit their own species (intraspecific brood parasitism) or a different species (interspecific brood parasitism), and parasitism may be a facultative or obligate strategy (Davies 2000). Interactions between interspecific brood parasites and their hosts may lead to coevolutionary arms races in which host species evolve defenses against parasitism, which select counteradaptations in parasites, further counteradaptations in hosts, and so on (Rothstein 1990, Davies 2000, Soler 2014).

In recent years, the complexity of coevolutionary arms races between brood parasitic birds and their hosts has become apparent. Evidence of coevolved adaptations and counteradaptations has been found at all stages of the host nesting cycle, from nest building through the egg, chick, and fledgling stages (Brooke \& Davies 1988, Langmore et al. 2003, Welbergen \& Davies 2009, De Mársico et al. 2012). Theory predicts that adaptations at one stage of the nesting cycle can influence evolution at other stages and lead to different coevolutionary trajectories in different host-parasite systems (Britton et al. 2007, Kilner \& Langmore 2011). Coevolutionary arms races may even account for global patterns of morphology and life history, such as high incidences of hawk mimicry (Gluckman \& Mundy 2013) and polymorphisms (Thorogood \& Davies 2013a) in cuckoos, and clutch sizes (Hauber 2003b) and social systems (Feeney et al. 2013) in hosts. Methodological advances, such as the use of light spectrophotometry and the development of bird visual perception models and pattern analysis techniques, are allowing more biologically accurate assessments of the proximate cues underlying coevolutionary processes (e.g., Cherry \& Bennett 2001, Stoddard \& Stevens 2011, Stoddard et al. 2014), and genetic techniques are unveiling the evolutionary histories of the interactions between the species (Gibbs et al. 2000, Sorenson \& Payne 2002, Fossøy et al. 2011, Spottiswoode et al. 2011).

This review synthesizes the recent key advances in understanding the depth of coevolution between avian obligate interspecific brood parasitic birds and their hosts. First, we discuss the evolution of obligate interspecific brood parasitism (henceforth "brood parasitism" or "parasitism," unless otherwise stated) as a breeding strategy and the phylogenetic history of brood parasite-host interactions (Sections 2.1 and 2.2). Next, we consider reciprocal adaptations and counteradaptations in brood parasites and their hosts at each stage of the host nesting cycle: before deposition of the parasitic egg in the host nest (the "frontline" of the arms race) (Section 3.1), during egg laying and incubation by the host (egg stage) (Section 3.2), following hatching, but while the chick(s) still resides within the nest (chick stage) (Section 3.3), and while the fledged chick(s) is still dependent on the parents (fledgling stage) (Section 3.4). Finally, we discuss the evolution of adaptive portfolios (cumulative suites of defensive adaptations in hosts 
and offensive adaptations in brood parasites) (Section 4.1) and the possible long-term outcomes of the coevolutionary interactions between brood parasites and hosts (Section 4.2). Promising future research prospects are highlighted throughout.

\section{THE EVOLUTION OF OBLIGATE INTERSPECIFIC BROOD PARASITISM IN BIRDS}

Obligate interspecific brood parasitism is the breeding strategy of approximately $1 \%$ of bird species (Davies 2000). It has evolved independently seven times in four orders: twice in the old-world cuckoos (Cuculiformes: Cuculinae) and once each in the new-world cuckoos (Cuculiformes: Neomorphininae), blackbirds (cowbirds: Passeriformes: Icteridae), old-world finches (Passeriformes: Ploceidae), honeyguides (Piciformes: Indicatoridae), and ducks (Anseriformes: Anatidae) (Sorenson \& Payne 2002).

\subsection{The Evolution of Interspecific Brood Parasitism as a Breeding Strategy}

With the exception of the black-headed duck, Heteronetta atricapilla, all avian obligate interspecific brood parasites are altricial (Davies 2000). This bias may be due to the considerable benefits that brood parasitism confers to altricial species, which produce relatively cheap hatchlings that require substantial attention posthatching, relative to their precocial counterparts, which are comparatively costly to produce but require less attention following hatching (Lyon \& Eadie 1991, Yom-Tov 2001).

Interspecific brood parasitism is considered to have arisen from intraspecific brood parasitism (Hamilton \& Orians 1965, Lyon \& Eadie 1991, Robert \& Sorci 2001), although this remains a contentious issue (e.g., Yom-Tov \& Geffen 2006). The majority of facultative interspecific brood parasites are also intraspecific parasites, and among altricial birds facultative interspecific parasitism is found in the same families as obligate interspecific brood parasitism (Lyon \& Eadie 1991, Yom-Tov 2001, Lyon \& Eadie 2008). In the precocial black-headed duck, there is mounting evidence that interspecific brood parasitism evolved from intraspecific brood parasitic ancestors (Lyon \& Eadie 2008). Among the other interspecific brood parasite lineages, disagreement will likely endure until a more comprehensive understanding of the breeding ecologies of the relevant species exists (Lyon \& Eadie 1991, Sorenson \& Payne 2002, Yom-Tov \& Geffen 2006). For example, there is limited to no information on the breeding ecologies of a large number of nonparasitic cuckoos (Payne 2005b) and a need for baseline natural history research.

Regardless of the ancestral parental mode, it is likely that obligate brood parasitism arose from facultative brood parasitism (Hamilton \& Orians 1965). The idea that nest predation can lead to opportunistic brood parasitism has received experimental support in both an intraspecific (Shaw \& Hauber 2009) and interspecific (Shaw et al. 2014) context. The idea that unusually favorable environmental conditions can result in an overproduction of viable eggs and promote facultative interspecific brood parasitism is supported by field studies (Lyon \& Eadie 1991) and theoretical models (Robert \& Sorci 2001) but awaits experimental confirmation. A variety of estrildid finches (close relatives of the parasitic finches) and the baywing, Agelaioides badius (a close relative of the cowbirds), use the old nests of other species as their own, and this has spurred ideas that brood parasitism can arise from nest usurpation (Davies 2000, Sorenson \& Payne 2002).

There are several life-history attributes that appear to predispose species to make the transition from intraspecific brood parasitism to obligate interspecific brood parasitism. Among cuckoos, it has been suggested that the evolution of brood parasitism was preceded by increased migratory behavior, increased breeding size range, and consumption of smaller prey items (Krüger \& Davies 
2002). Each of these changes in ecology may have favored breeding strategies that reduce the costs of reproduction (Krüger \& Davies 2002). It seems likely that the ancestors of the cuckoos, cowbirds, and honeyguides had shorter incubation periods than their primary hosts before the evolution of brood parasitism, which is an attribute that would increase the likelihood of successful competition with nest mates (Hamilton \& Orians 1965, Payne 2005b). Internal incubation is exhibited by at least some cuckoos (Cuculus sp.) and the greater honeyguide, Indicator indicator, but not in the cuckoo finch, Anomalospiza imberbis (Birkhead et al. 2011). In the cuckoos, internal incubation has not arisen as an adaptation to brood parasitism but may have facilitated its evolution, whereas in the greater honeyguide internal incubation may have arisen as an adaptation to brood parasitism (Birkhead et al. 2011).

\subsection{The Phylogenetic History of Interspecific Brood Parasitism}

Of the seven currently recognized independent evolutionary origins of brood parasitism, five (cuckoos, finches, and honeyguides) are relatively old (>5 Myr), whereas two (the cowbirds and ducks) are relatively young ( $<5$ Myr) (Sorenson \& Payne 2002). Speciation events among brood parasite lineages can be ancient, such as the split between the cuckoo finch and the other parasitic finches (Viduidae) (in the vicinity of 13 Myr; Sorenson et al. 2004), and others are relatively recent, as in some indigobird species (Sorenson et al. 2003). Additionally, avian brood parasites exhibit higher rates of speciation, extinction, and molecular evolution than their nonparasitic counterparts (Sorenson \& Payne 2002, Krüger et al. 2009). Although rarely estimated (Gibbs et al. 2000, Spottiswoode et al. 2011), the duration of relationships between brood parasites and hosts shows much variation: approximately $3 \mathrm{Myr}$ for some races of the greater honeyguide and its hosts (Spottiswoode et al. 2011); 65,000-80,000 years for some races of the common cuckoo, Cuculus canorus, and its hosts (Gibbs et al. 2000); and recent colonization of new host species by some indigobird species (Sorenson et al. 2003).

The rich and dynamic phylogenetic history of avian interspecific brood parasitism implicates coevolution with hosts as a strong driver of biological diversity (Sorenson \& Payne 2002, Krüger et al. 2009, Krüger \& Kolss 2013). This has similarly been suggested in studies of experimental coevolution in the laboratory (Brockhurst \& Koskella 2013). However, evidence of higher rates of molecular evolution in hosts, and evidence of speciation or extinction in brood parasites or hosts because of coevolutionary interactions, is still lacking and is an important prospect for future work.

\section{COEVOLUTIONARY DYNAMICS BETWEEN BROOD PARASITES AND HOSTS}

Interspecific brood parasitism provides an interesting model for studying a variety of ecological phenomena, such as how species interactions are affected by a changing environment (Møller et al. 2011); however, the coevolutionary arms races between brood parasites and their hosts continue to attract the most attention. Below we consider the adaptations and counteradaptations that have evolved in brood parasites and hosts at all stages of the host nesting cycle.

\subsection{Frontline Adaptations}

Successful brood parasitism hinges on the ability of the parasite to deposit its egg in the host nest. Correspondingly, deterring laying by the parasite is of utmost importance to the hosts, because at this stage they can avoid most of the costs associated with being parasitized. This frontline of the arms race is defined as the adaptations and counteradaptations that operate before insertion of the parasite egg in the host nest (Welbergen \& Davies 2009, Feeney et al. 2012). 
Frontline defenses often depend on hosts recognizing adult brood parasites (but not always; see, e.g., Canestrari et al. 2009). This appears to be a learned attribute (Langmore et al. 2012, Feeney \& Langmore 2013) that is associated with specific morphological cues of the parasite, such as conspicuous eye rings or barred underparts (e.g., Trnka et al. 2012). Recognition and mobbing of brood parasites can be acquired through social learning from conspecifics (Davies \& Welbergen 2009, Feeney \& Langmore 2013), and social learning may be even more important than personal experience in this context (Campobello \& Sealy 2011). Hosts may assess the risk of parasitism before laying by using information acquired directly from a parasite (Davies \& Brooke 1988, Hosoi \& Rothstein 2000, Forsman \& Martin 2009, Kleindorfer et al. 2013), from environmental cues that correlate with parasitism (Welbergen \& Davies 2009, Patten et al. 2011), or both (Welbergen \& Davies 2012). Assessments of parasitism risk can be used to determine where to nest (Forsman \& Martin 2009), the appropriate level of nest vigilance (Davies et al. 2003), or whether defenses should be deployed, at either the frontline (Welbergen \& Davies 2012) or later stages of the nesting cycle (Davies \& Brooke 1988, Hosoi \& Rothstein 2000, Langmore et al. 2009a). Some host species have alarm calls that specifically denote a parasite (Gill \& Sealy 2004, Feeney et al. 2013). Others produce a more urgent version of a generalized alarm response (Neudorf \& Sealy 1992, Welbergen \& Davies 2008) or do not appear to react to brood parasites as unique from other nest threats (Neudorf \& Sealy 1992).

Many host species physically attack or mob brood parasites with potentially lethal aggression (Gloag et al. 2013). This behavior can be beneficial to hosts as it can successfully deter laying by a brood parasite (Davies \& Welbergen 2009, Feeney et al. 2013, Gloag et al. 2013, but see Smith et al. 1984) or reduce the degree of destruction done by the parasite to the host clutch during the laying visit (Gloag et al. 2013). Alternatively, some hosts are more passive-aggressive, and may decrease the opportunity for parasitism by spending more time on the nest, physically blocking the parasite from laying (Gill \& Sealy 2004, Canestrari et al. 2009). Empirical studies suggest that there is strength in numbers, as hosts in large colonies or cooperative groups are less likely to be parasitized (Brown \& Lawes 2007, Canestrari et al. 2009, Feeney et al. 2013), and the protection conferred by larger groups may favor cooperative breeding in host species (Feeney et al. 2013).

Hosts may defend against parasitism through inhibitory (Davies 2000, Grim et al. 2011) or deceptive (Soler et al. 1999) nest structures or by nesting in locations that deter parasitism (e.g., Patten et al. 2011). Alternatively, some hosts may dilute the risk of parasitism by aggregating nests in space and synchronizing breeding to swamp the parasite or facilitate group nest defense (e.g., Clark \& Robertson 1979), and it is suspected that some may also avoid parasitism by shifting their breeding phenology relative to that of the parasite (e.g., Brooker \& Brooker 1989).

As hosts have evolved defenses that help deter deposition of the parasite egg in their nests, brood parasites have evolved counteroffenses. Adult parasites whose progeny eliminate the host brood following hatching appear to rely heavily on deceptive or cryptic adaptations to circumvent host defensive adaptations. This may be because these hosts have a greater incentive to abandon their nests as parasitism generally results in the destruction of their entire breeding attempt and carries the additional costs of raising the alien chick(s), time that could otherwise be used to initiate a new breeding attempt. Brood parasites can decrease the likelihood of being identified by evolving cryptic plumages (Krüger et al. 2007), plumages that mimic dangerous heterospecifics (Davies \& Welbergen 2008, Gluckman \& Mundy 2013), or plumage polymorphisms (Honza et al. 2006, Thorogood \& Davies 2012, Thorogood \& Davies 2013a, Trnka \& Grim 2013). Some evolve cryptic behaviors, such as observing host nests from hidden or distant perches (Honza et al. 2002), approaching host nests at times of day when hosts are absent (Davies 2000), or targeting specific host breeding pairs or groups to minimize the likelihood of being detected (Soler et al. 1999, but see Antonov et al. 2012). 
A recent series of studies demonstrated a particularly intricate suite of adaptations and counteradaptations between cuckoos and their hosts at the frontline of the arms race. Common cuckoos appear to have evolved hawk, Accipiter sp., mimicry to reduce the likelihood of being mobbed by their hosts (Welbergen \& Davies 2011). However, at least some host individuals can discriminate cuckoos from sparrowhawks in some situations (Davies \& Welbergen 2008, Trnka \& Prokop 2012), and such discrimination can be rapidly transmitted through host populations through social learning (Davies \& Welbergen 2009, Thorogood \& Davies 2012). In response, common cuckoos have evolved plumage polymorphisms that can reduce host mobbing of the rare morph (Honza et al. 2006, Thorogood \& Davies 2012). Moreover, a recent study by Thorogood \& Davies (2013a) suggests that this process may explain the high global incidence of polymorphisms in hawk-mimicking cuckoo species.

Brood parasites whose progeny do not annihilate the entire host brood may also exhibit deceptive adaptations that facilitate parasitism; however, they also use more direct and forceful means of gaining access to host nests. There is evidence that some of these parasites damage host eggs before laying to provide a competitive edge to their offspring and possibly assess nest suitability (Massoni \& Reboreda 1999, Gloag et al. 2013), locate potential host nests by "flushing" the host from the nest, exhibit male-female cooperation, or simply push the defending hosts off their nest to allow parasitism (reviewed by Davies 2000, Feeney et al. 2012). Such adaptations are less likely to evolve in parasites that eliminate the host brood upon hatching, as the host receives no fitness by accepting the parasitic offspring and can abandon the nest to renest. Interestingly, Gloag et al. (2013) found that mobbing of shiny cowbirds, Molotbrus bonariensis, by mockingbirds, Mimus saturninus, during laying was extremely common ( $80 \%)$ and brutal, but was endured by the cowbirds until they had successfully laid their egg. These results may suggest that these parasites have evolved the ability to withstand mobbing, possibly through a thicker skin or a denser skull. Although this has not yet been demonstrated in avian brood parasites, analogous adaptations exist in brood parasitic insects (reviewed by Kilner \& Langmore 2011).

\subsection{Egg-Stage Adaptations}

If the parasite successfully deposits its egg in the host nest, the egg stage of the arms race ensues. Adaptations at this stage of the host nesting cycle comprise the best-studied examples of brood parasite-host coevolution (Rothstein 1990, Davies 2000, Soler 2014).

A parasitic egg in the nest may result in partial or complete destruction of the host brood upon hatching, as well as the redirection of resources to the parasite. Consequently, hosts have evolved defenses against parasitic eggs that minimize the costs of brood parasitism. Host defenses generally rely on discrimination of the parasitic egg(s) in a clutch, which appears to be mediated by two cognitive mechanisms: comparing the eggs in the nest to an internal template of the appearance of the host's own eggs (true recognition; Rothstein 1975, Lotem et al. 1995, Lahti \& Lahti 2002) or identifying the odd egg, or eggs, in its clutch (discordancy hypothesis; Rothstein 1975, Marchetti 2000). Recent work by Moskát et al. (2010) and Bán et al. (2013) investigating the great reed warbler, Acrocephalus arundinaceus (a host of the common cuckoo), and Stevens et al. (2013) investigating the tawny-flanked prinia, Prinia subflava (a host of the cuckoo finch), found that both mechanisms contribute to identification of the parasitic egg(s), presumably mitigating the weaknesses inherent in either mechanism.

Recognition of an odd egg in the nest is achieved by perceiving differences in the phenotypes between the parasite and host eggs, and the response to these differences can be affected by the perceived risk of parasitism (see above). Hosts are known to identify a parasitic egg(s) in 
their nest according to differences in egg color (Rothstein 1982, Brooke \& Davies 1988, Avilés et al. 2010, Spottiswoode \& Stevens 2010, Stoddard \& Stevens 2011, Bán et al. 2013), pattern (Spottiswoode \& Stevens 2010, Stoddard \& Stevens 2010, Stoddard et al. 2014), size (Marchetti 2000, Langmore et al. 2003), and shape (Mason \& Rothstein 1986) and by the arrangement of the eggs in the nest (Polačiková et al. 2013) or a combination of these attributes (Rothstein 1982, Lahti \& Lahti 2002, Spottiswoode \& Stevens 2010, Stevens et al. 2013). Recent techniques allow quantitative measurements of color (Cherry \& Bennett 2001, Starling et al. 2006) and pattern (Stoddard \& Stevens 2010, Stoddard et al. 2014), which can be used to calibrate models to account for bird visual systems (Cassey et al. 2008, Avilés et al. 2010, Spottiswoode \& Stevens 2010, Stoddard \& Stevens 2011). Notably, Cherry \& Bennett (2001) found that human subjects were unable to identify hidden aspects of egg mimicry by red-chested cuckoos, Cuculus solitarius, that could be determined using reflectance spectrophotometry, highlighting the importance of using more objective measurement techniques (also see Starling et al. 2006). However, no studies have investigated whether discrimination occurs according to the olfactory profiles of host and parasite eggs (but see Soler et al. 2014).

Once the odd egg(s) has been recognized, hosts can either accept or reject it. Egg rejection comprises either physical ejection of the odd egg from the nest (Brooke \& Davies 1988, Davies \& Brooke 1989a, Moksnes et al. 1991, Spottiswoode \& Stevens 2010), burying the parasitic egg in the nest lining (Davies \& Brooke 1988, Langmore et al. 2003), building a new nest on top of the clutch containing the parasitic egg (Davies \& Brooke 1988), or deserting the parasitized nest (Davies \& Brooke 1989a, Hosoi \& Rothstein 2000, Welbergen et al. 2001, Langmore et al. 2005). Hosts can physically remove a parasitic egg by grasping the entire egg with their bill (grasp ejection) (Moksnes et al. 1991), puncturing the egg and ejecting it from the nest by grasping it by the shell with their bill (puncture ejection) (Rohwer \& Spaw 1988, Moksnes et al. 1991), or grasping and removing the egg with their feet (De Mársico et al. 2013).

Whether a species accepts or rejects a parasitic egg typically depends on the duration of exploitation by brood parasites (Hosoi \& Rothstein 2000), physical capabilities of the species, the costs and benefits of the various defensive behaviors, and external pressures. Visibility within the nest appears to affect the rejection rate of parasitic eggs by hosts, who may have difficulty detecting foreign eggs in dark nests (Langmore et al. 2009b, Antonov et al. 2011). Rejection may also depend on bill size relative to the size and thickness of the parasite egg (Rohwer \& Spaw 1988, Moksnes et al. 1991, but see Underwood \& Sealy 2006). Acceptance of the parasite egg is more likely if the costs or perceived risk of parasitism are low, such as when parasitism occurs late after egg laying (Welbergen et al. 2001, Langmore et al. 2003), or when the cost of defenses is high, such as when parasitism does not result in the complete destruction of the host brood or the likelihood of nest predation is high (Krüger 2011).

One study on egg rejection suggests that hosts can acquire defenses against brood parasites more rapidly than would be possible through genetic adaptation. In azure-winged magpies, Cyanopica cyana, egg rejection defenses were expressed less than 20 years after parasitism by the common cuckoo commenced (Nakamura et al. 1998). This is considered too brief a time period to be the outcome of genetic change, and learning has been proposed as an alternative mechanism underlying egg rejection (Nakamura et al. 1998, Soler 2011).

Brood parasites have evolved a suite of adaptations to counteract the defenses of their hosts at the egg stage. As mentioned above, some have evolved eggs that mimic the color (Rothstein 1982, Brooke \& Davies 1988, Avilés et al. 2010, Spottiswoode \& Stevens 2010, Stoddard \& Stevens 2011, Bán et al. 2013, Feeney et al. 2014), pattern (Spottiswoode \& Stevens 2010, Stoddard \& Stevens 2010, Stoddard et al. 2014), size (Marchetti 2000, Krüger \& Davies 2002) and shape 
(Mason \& Rothstein 1986) of the host eggs, as more mimetic eggs are rejected less (Cassey et al. 2008, Spottiswoode \& Stevens 2010). Defenses by multiple host species have driven the evolution of genetically distinct races (gentes) in brood parasites, each possessing an egg phenotype that matches that of their favored host(s) (Gibbs et al. 2000, Fossøy et al. 2011, Spottiswoode et al. 2011; for a list of brood parasite and host species that possess races see Langmore \& Spottiswoode 2012). Alternatively, defenses by multiple host species may drive generalist mimicry in the eggs of brood parasites (Edvardsen et al. 2001, Stoddard \& Stevens 2010, Feeney et al. 2014). Recently, Spottiswoode \& Stevens (2012) presented elegant correlational evidence from an extensive egg collection that showed that cuckoo finch and tawny-flanked prinia egg phenotypes have undergone rapid but closely tracked changes in their appearance over a 40-year period, suggestive of coevolutionary processes that may underpin race formation in both parasites and hosts (also see Lahti 2005).

The mode of inheritance and evolutionary stability of host-specific egg phenotypes are not well understood, and research is currently limited to two brood parasite systems: the greater honeyguide and the common cuckoo (Gibbs et al. 2000, Fossøy et al. 2011, Spottiswoode et al. 2011). In the greater honeyguide, there is evidence that host-specific egg phenotypes are maternally inherited and that host-specific races have been stable for millions of years (Spottiswoode et al. 2011). By contrast, race formation in the common cuckoo evolved relatively recently (Gibbs et al. 2000). In this species there is evidence of assortative mating in some populations (Fossøy et al. 2011) but not in others (Gibbs et al. 2000). Whether stable host-specific races evolve or speciation occurs depends on the frequency of assortative mating (Krüger \& Kolss 2013), which may differ between populations because of the relative density, extent of sympatry, and breeding synchrony of host species (Fossøy et al. 2011). Additionally, though it seems likely that host specific phenotypes in brood parasite races are determined by genes on the $W$ chromosome, and therefore passed from mother to daughter, this has not been demonstrated directly. An important future line of research is to establish directly that host races are maintained maternally through the following: captive breeding experiments, identifying genetic offspring by using ancient DNA techniques from philopatric brood parasites through generations from egg collections (Spottiswoode et al. 2011), or following and sampling females and their offspring of different philopatric brood parasite races in the field.

Mimicry of host eggs is not the only adaptation of brood parasites to prevent egg rejection by hosts. Several Australasian bronze-cuckoo species that parasitize dome-nesting hosts lay darkcolored eggs that appear to be invisible to hosts inside their dark nests (Langmore et al. 2009b). Visual modeling analyses reveal that this egg phenotype is cryptic in the host nest when seen through a bird's eye and may be an adaptation that decreases the likelihood of detection of the egg by the host or a competing brood parasite (Langmore et al. 2009b, Gloag et al. 2014, and also see Spottiswoode 2013). There is also some evidence that brood parasites may dupe their host(s) into accepting their eggs by producing nonmimetic, but attractive, egg phenotypes (Alvarez 1999). Some brood parasites produce eggs with thick shells, which may make puncturing more difficult for hosts (Rohwer \& Spaw 1988, Moksnes et al. 1991, Mermoz \& Ornelas 2004) and other competing brood parasites (Brooker \& Brooker 1991, Moksnes et al. 1991, Spottiswoode 2013), and some have also evolved a shorter-than-expected incubation time to give their chick a competitive edge over their nest mates (Briskie \& Sealy 1990). Finally, some brood parasites "farm" host nests, which involves depredation of host nests that are too far advanced for parasitism (Arcese et al. 1996), or employ "mafia" behaviors, which involves destruction of host nests that reject parasitic eggs (Zahavi 1979, Soler et al. 1995, Hoover \& Robinson 2007), as both behaviors force renesting by the host.

As parasites have evolved strategies that manipulate their host(s) into accepting their eggs, hosts have responded with further counteradaptations. Some hosts of the greater honeyguide possess 
thicker eggshells to help protect their eggs against egg puncturing by the parasite (Spottiswoode \& Colebrook-Robjent 2007). Others have evolved decreased intraclutch variation in egg appearance (reviewed by Langmore \& Spottiswoode 2012) and increased between-clutch variation (Stokke et al. 2002, Honza et al. 2004, Spottiswoode \& Stevens 2011). Both of these increase the likelihood of detection of parasitic eggs by hosts (e.g., Stokke et al. 1999, 2002) and decrease the potential for egg phenotype-matching by the parasite (e.g., Cherry et al. 2007, but see Antonov et al. 2012). Finally, the disruptive selection on host egg phenotypes imposed by brood parasites can escalate to the evolution of egg "signatures" (Spottiswoode \& Stevens 2010, Stoddard et al. 2014).

Following other exploiter-victim systems, defensive adaptations have recently been placed into one of two categories: resistance, in which the host evolves adaptations to reduce the parasite load directly, or tolerance, in which the host endures parasitism but evolves adaptations that limit its harm (Kilner \& Langmore 2011, Soler et al. 2011). So far we have discussed strategies of resistance against parasites by hosts; however, strategies of tolerance, though comparatively little studied, have been demonstrated at the egg stage of the nesting cycle for a number of species. For example, the great spotted cuckoo, Clamator glandarius, usually damages host eggs during laying (Soler \& Soler 2000). The magpie, Pica pica, which hosts this cuckoo, has evolved large clutch sizes that counteract the impact of parasitism. The cuckoo is reared alongside the host young, so parasitized magpies with larger clutches can produce more of their own young than those with smaller clutches (Soler \& Soler 2000, Soler et al. 2011). Conversely, if survival of host young is low in parasitized nests, hosts might benefit from producing more small clutches rather than few large clutches to avoid "putting all their eggs in one basket" (Hauber 2003b). This has been demonstrated in brown-headed cowbird, Molothrus ater, hosts, in which hosts with a longer evolutionary history with the parasite produce smaller clutches and make more breeding attempts than the more recent hosts (Hauber 2003b).

\subsection{Chick-Stage Adaptations}

The past decade or so has seen a paradigm shift, from doubts that hosts of brood parasites discriminate and retaliate against parasite nestlings (Rothstein 1990, Lotem 1993, Davies 2000) to discoveries of parasite nestling discrimination in some systems and corresponding adaptations by parasites. This shift has consequentially led to incorporation of this stage of the nesting cycle in the understanding of coevolution between these species (Langmore et al. 2003, Grim 2011).

Many host species fail to discriminate against enormous parasitic chicks in their nests. An explanation for this observation was presented in an influential model by Lotem (1993), who demonstrated that if discrimination of parasitic nestlings occurs through imprinting on own young, then nestling discrimination should not evolve in brood parasite hosts owing to high costs of misimprinting. Subsequent discoveries of cuckoo chick rejection by hosts provide indirect support for this theory because hosts appear to rely at least in part on "recognition-free" mechanisms for discrimination, thereby avoiding the misimprinting costs inherent in recognition-based systems (Langmore et al. 2003, Grim 2007). Langmore et al. (2003) found that the primary cue for chick abandonment in the superb fairy-wren, Malurus cyaneus, is the presence of a lone chick in the nest, and Grim (2007) found that reed warblers abandon chicks that take an atypically long time to fledge. The use of these cues alleviates the need for an imprinting-based mechanism and is highly reliable because, unlike host broods, cuckoo chicks in these systems are always alone in the nest (Langmore et al. 2003) and take longer to fledge than host young (Grim 2007). Subsequent work has shown that superb fairy-wrens further reduce the likelihood of mistakenly rejecting a fairy-wren chick by relying on visual and acoustic cues from nestlings (Langmore et al. 2003, 2008) as well as their perceived risk of parasitism (Langmore et al. 2009a). 
Rejection of parasite nestlings may take the form of abandonment (Langmore et al. 2003, Grim 2007), allocation of lower quality or quantity of food (reviewed by Grim et al. 2011), pecking the parasitic chick (reviewed by Grim et al. 2011), or physically evicting the newly hatched parasite (Sato et al. 2010b, Tokue \& Ueda 2010). Unlike other forms of chick rejection, eviction of the parasite chick can salvage at least some of the host's own brood if it is performed before the parasite evicts the host progeny. Sato et al. (2010b) demonstrated that this is possible in gerygone (Gerygone spp.) hosts of little bronze-cuckoos, Chalcites minutillus, which evict the parasite chick within hours of hatching. Other suspected cases of nestling discrimination exist in a range of systems (reviewed by Grim et al. 2011), which all require confirmation.

Following hatching, nestling parasites adopt one of two broad strategies in the host nest: some usurp the entire parental effort of their foster parents by eliminating the host brood, whereas others are raised alongside their foster siblings (Davies 2000, Kilner \& Langmore 2011). Which of these alternatives is adopted depends on which maximizes provisioning to the parasitic chick (Kilner et al. 2004, Gloag et al. 2011). Elimination of the host brood by the newly hatched parasite is generally achieved by heaving the remaining eggs and chicks from the nest, as seen among the majority of Old World cuckoos (with the exception of the Clamator, Scythrops and Eudynamys species) or by using sharp bill hooks to actively swipe at and kill the host brood, as seen in the New World cuckoos and honeyguides (Davies 2000, Spottiswoode \& Koorevaar 2011). Eviction of the host eggs is costly for a young cuckoo (e.g., Anderson et al. 2009a), but it appears an important strategy for at least common cuckoos that are not competitive in a mixed brood and experience higher growth and survival rates when reared alone (e.g., Geltsch et al. 2012). The costs of evicting or competing with nest mates can be recovered if the cuckoo survives in some cases (Anderson et al. 2009a, Geltsch et al. 2012). To date, the importance of monopolization of parental provisioning effort in parasitic species has attracted little study outside cuckoo-host and cowbird-host systems.

Alternatively, some parasites do not require elimination of the host brood to achieve adequate provisioning. These species include the cowbirds, finches, and some parasitic cuckoos. Nest cohabitation seems to be associated with the relative size between parasite and host, as relatively large parasites are better able to gain sufficient food while sharing their nest with their smaller nest mates (Soler \& Soler 1991, Hauber 2003a, Gloag et al. 2011). Among brown-headed and shiny cowbirds, the presence of host chicks is actually beneficial to the parasite chick because a larger brood size increases the rate of provisioning by host parents, and the parasite is able to monopolize most parental feeds (Kilner et al. 2004, Gloag et al. 2011). In some cases, these parasites can compete so effectively for food that their foster siblings starve to death (Soler \& Soler 1991, Hauber 2003a, Kilner et al. 2004). The competitiveness of cowbird chicks seems to be an adaptation to brood parasitism (Hauber 2003a).

Brood parasitic chicks that reject their host nest mates or cohabit with the host chicks exhibit counteradaptations that help circumvent host defenses and ensure adequate provisioning. In response to rejection of parasite chicks by hosts, some nestling cuckoos have evolved mimicry of host nestling morphology (Langmore et al. 2011), and a variety of parasitic chicks produce begging calls that resemble those of host young (Langmore et al. 2008, Anderson et al. 2009b, De Mársico et al. 2012). Here, cuckoo chicks may learn to reproduce the begging calls of their host species through fine-tuning an initially variable call to the structure that elicits the greatest provisioning response from the host parent (Madden \& Davies 2006, Langmore et al. 2008) or helps them evade detection and rejection (Langmore et al. 2003) or both (Langmore et al. 2003, 2008). Parasitic chicks can also exploit the sensory biases of their hosts to elicit increased provisioning rates with exaggerated visual or vocal displays (Briskie et al. 1994, Kilner et al. 1999). A remarkable example of this is demonstrated by the Horsfield's hawk-cuckoo, Cuculus fugax. Nestlings of this species 
possess a gape-colored skin patch on each wing that is presented to the host, alongside its actual gape, to simulate multiple gaping mouths and elicit increased provisioning from its hosts (Tanaka \& Ueda 2005, Tanaka et al. 2011).

Although relatively little studied, competition with brood parasites appears to have selected for further counteradaptations in host nestlings. Nestlings of cowbird hosts, which are reared alongside the parasite chick, generally experience accelerated growth rates, shorter nesting periods, and lower mass at fledging compared with those not parasitized by cowbirds (Remeŝ 2006), representing additional possible examples of tolerance to parasitism (Kilner \& Langmore 2011, Soler et al. 2011). Furthermore, evidence is accumulating that parasitism can also select exaggerated begging calls in cowbird hosts (Briskie et al. 1994, Pagnucco et al. 2008). However, Anderson et al. (2009b) found no evidence of divergence in gray warbler, Gerygone igata, nestling begging calls because of begging call mimicry by cuckoos, suggesting that these types of host responses to brood parasitism may only occur in some situations.

An intriguing possibility is that coevolution at the chick stage has selected for host nestling mimicry of parasite nestlings (Hauber \& Kilner 2007). Nestlings of the estrildid finches of Africa exhibit highly varied and elaborate mouth markings that are mimicked by parasitic Vidua finches. Payne (2005a) demonstrated that host species have more colorful nestling mouths than unparasitized estrildid species, suggesting that nestling morphology has evolved away from that of the parasite, facilitating discrimination of parasite chicks by host parents. Hauber \& Kilner (2007) proposed an alternative mechanism. They suggested that parasite chicks are under stronger selection for such exaggerated signals than host young because brood parasites have no genetic stake in the survival of host parents or nest mates. This may give rise to the paradoxical situation in which nestling parasites evolve exaggerated mouth markings that extract more food from host parents, causing selection for mimicry in host nestlings (Hauber \& Kilner 2007). Either way, this system suggests the existence of counteradaptations in host nestlings in response to mimicry by nestling parasites.

\subsection{Fledgling-Stage Adaptations}

Fledglings of altricial species require care following emergence from the nest, and evidence suggests that coevolutionary interactions between brood parasites and their hosts also occur during this period. Most notably, De Mársico et al. (2012) found that visual and vocal mimicry of baywing fledglings by fledgling screaming cowbirds, Molotbrus rufoaxillaris, their primary parasite, maintains host provisioning and increases parasite survival compared with the less mimetic fledglings of their secondary parasite, the shiny cowbird. This is the only experimental evidence of brood parasite-host coevolution at this stage of the breeding cycle.

Allusions to potential coevolved adaptations in fledgling brood parasites and their hosts exist in the literature. Sanjeeva Raj (1964) noted an observation of a fledgling Jacobin cuckoo, Clamator jacobinus, that was ignored by its yellow-billed babbler, Turdoides affinis, foster group after fledging, possibly suggesting fledgling discrimination. Hoskin (1989) compiled a series of anecdotal observations on interactions between fledgling black-eared cuckoos, Chalcites osculans, and a variety of species that also suggested fledgling cuckoo abandonment. Hoskin also noted that, on occasion, fledgling black-eared cuckoos received provisioning from a variety of species in addition to their host parents (Hoskin 1989). Although these notes are anecdotal, they suggest that host defenses against fledgling brood parasites may exist and that fledgling brood parasites may exploit the sensory predispositions of their foster parents (as well as other individuals and species), providing the means for further escalation of the coevolutionary arms race at the fledgling stage of the host nesting cycle. 


\section{COEVOLUTIONARY PROCESSES AND OUTCOMES}

\subsection{The Evolution of Adaptive Portfolios and Interactions Between Levels of the Arms Race}

One of the greatest puzzles of brood parasitism is that many birds are able to recognize and reject a parasitic egg that is a nearly perfect mimic of their own, but are unable to recognize and retaliate against an often dissimilar-looking parasitic chick (Davies 2011). Why are some adaptations and counteradaptations present at some stages of the nesting cycle but absent in others? Recent attention to this question has returned theoretical explanations mostly revolving around ideas known as strategy blocking (Britton et al. 2007) and strategy facilitation (Kilner \& Langmore 2011). Strategy blocking refers to adaptations at one stage of the arms race (e.g., egg rejection) that relax selection for defenses at another stage (e.g., at the frontline, chick, or fledgling stages). The corollary, strategy facilitation, refers to selection for adaptations at one stage of the nesting cycle (e.g., recognition of adult brood parasites) that may in turn facilitate the evolution of adaptations at other stages (e.g., recognition of egg, chick, or fledgling parasites). These ideas are theoretically plausible but difficult to demonstrate.

In theory, strategy blocking occurs when effective host defenses at one stage of the arms race relax selection defenses at another. This process would be predicted to operate when one defense is highly effective and defenses at other stages carry substantial costs. Strategy blocking may explain why some populations of reed warblers, Acrocephalus scirpaceus, reject common cuckoo eggs but not chicks or fledglings and why superb fairy-wrens reject cuckoo chicks but not eggs (Britton et al. 2007, Kilner \& Langmore 2011). This process may similarly provide a plausible explanation for the lack of these defenses in many other host species; however, this will be difficult to determine until better evidence of the presence or lack of defenses at later stages of the nesting cycle becomes available (Grim 2011).

Hosts may also lack defenses at some stages of the nesting cycle for reasons other than, or in addition to, strategy blocking. The lack of egg rejection by many hosts may be explained by benefits of retaining parasite eggs to prevent damage (Gloag et al. 2012), costs of removal of host eggs during subsequent parasitism events (Sato et al. 2010a), suppression of rejection behavior by vindictive parasites (Zahavi 1979, Soler et al. 1995, Hoover \& Robinson 2007), physical constraints on egg recognition (Langmore et al. 2005, Antonov et al. 2011) or rejection (Moksnes et al. 1991, Underwood \& Sealy 2006, Krüger 2011), or evolutionary lag following recent range expansions or low parasitism rates by brood parasites (Davies 2000).

There are also possible examples of strategy facilitation in the literature (Kilner \& Langmore 2011). The ability of hosts to recognize adult brood parasites as unique from other species may have predisposed hosts to evolve discrimination against parasitic eggs or chicks (Kilner \& Langmore 2011). However, as with strategy blocking, strategy facilitation appears intrinsically difficult to demonstrate in practice. In the future, a comprehensive understanding of host defenses at all stages of the nestling cycle for multiple host species will allow broadscale comparative analyses investigating whether those hosts with effective defenses at one stage of the arms race are more or less likely to evolve defenses at other stages.

\subsection{The Outcomes of Coevolutionary Interactions Between Brood Parasites and Hosts}

What are the long-term outcomes of the coevolutionary interactions between brood parasites and their hosts? Theory suggests that parasites and hosts may remain in ongoing interactions or one party will defeat the other (Davies \& Brooke 1989b, Rothstein 1990, Soler 2014). Ongoing 
interactions can take the form of a coevolutionary arms race or an evolutionary equilibrium between parasite and host that is determined by the relative costs and benefits of host defenses (Davies \& Brooke 1989b, Rothstein 1990, Lotem et al. 1995) and brood parasitism to the host (Canestrari et al. 2014). Defeat can take the form of host switching in parasites or extinction of either party (Krüger et al. 2009, Soler 2014).

In recent years, discoveries of adaptations and counteradaptations outside the egg stage (e.g., Langmore et al. 2003, Welbergen \& Davies 2009, De Mársico et al. 2012) have provided convincing evidence of coevolution at the other stages of the nesting cycle. In addition, the realization that coevolution can be expressed both within and between all stages (Welbergen \& Davies 2009) provides scope for arms races to continue beyond the constraints of a single stage. Directional arms races, in which host defenses and parasite offenses improve incrementally, may become constrained by insufficient genetic variation or physiological limitations at one stage but continue to escalate at other stages. Arms races may theoretically continue indefinitely if they become cyclical, that is, if trait frequencies in the parasite and the host are in a state of constant oscillation owing to frequency-dependent selection (e.g., Spottiswoode \& Stevens 2012), both within and between stages of the nesting cycle.

Soler (2014) suggested that host switching by parasites or extinction of either party may be more common than previously appreciated and that ongoing interactions may exist only as unstable transitional states. However, recent empirical evidence suggests that, in some circumstances, hosting a parasite can be beneficial and may provide an evolutionary pathway to long-term mutualistic interactions between host and brood parasite (Canestrari et al. 2014). The retention of egg rejection abilities by many currently nonparasitized host species was interpreted by Soler (2014) as suggesting that through evolutionary time, brood parasites are continually switching from initially more appropriate (but subsequently better defended) to initially less appropriate (but less well-defended) host species (Davies \& Brooke 1989b, Soler 2014, also see Thorogood \& Davies 2013b). If host switching by parasites or extinction of either party are common outcomes (Krüger et al. 2009, Soler 2014), this could provide an alternative explanation for why many host species exhibit defenses at the frontline and the egg stage while few appear to exhibit chick- or fledgling-stage defenses. Because the costs of brood parasitism accumulate throughout the nesting cycle (Davies 2011), this should slow the evolution of later-stage defenses relative to earlier-stage defenses, subject to evolutionary constraints (e.g., Rohwer \& Spaw 1988, Langmore et al. 2009b, Grim et al. 2011). Therefore, later-stage defenses are less likely to be observed, especially when ongoing evolutionary interactions are rare, and should be found predominantly in those brood parasite-host systems that have a long coevolutionary history. This prediction for the phylogenetic distribution of defenses awaits investigation.

It is clear that more research is needed into the presence and effectiveness of antibrood parasite defenses in both parasitized and unparasitized species at all stages of their nesting cycles. This will refine insights into how, and how often, brood parasite-host arms races are won or lost or how they escalate into ongoing interactions through evolutionary time.

\section{CONCLUSIONS}

The interactions between avian obligate interspecific brood parasites and their hosts provide informative models for the study of coevolutionary processes in the natural world. The ecological and evolutionary consequences of these relationships are profound; coevolved adaptations in brood parasites and their hosts are now evident at all stages of the host nesting cycle, and it is clear that these relationships can even predict global patterns in brood parasite morphology (Gluckman \& Mundy 2013, Thorogood \& Davies 2013a), and host clutch sizes (Hauber 2003b) and social 
systems (Feeney et al. 2013). These coevolutionary relationships also affect the rates of evolution of brood parasites (Sorenson \& Payne 2002), and future work may reveal that they are driving the evolution of species.

Despite the benefits of using avian brood parasite-host interactions to understand coevolutionary processes in the natural world, they also have inherent weaknesses. Notably, laboratory studies have the distinct advantage of enabling unequivocal identification of adaptations that have evolved in response to reciprocal selection; this provides an opportunity to observe coevolution in action (for a recent review of experimental coevolution in the laboratory see Brockhurst \& Koskella 2013). Surely, among the most fruitful paths to continue to probe the fundamental nature of coevolutionary interactions is to converse with other fields that share similar ambitions but comprise different model systems with inherently different attributes.

A robust framework now exists to integrate the diversity of host defense and parasite offense portfolios across the different stages of the nesting cycle to generate a more holistic understanding of brood parasite-host coevolution. The future is exciting, and further advances in the study of these fascinating systems will continue to unveil the ecological and evolutionary consequences of species interactions in the natural world.

\section{DISCLOSURE STATEMENT}

The authors are not aware of any affiliations, memberships, funding, or financial holdings that might be perceived as affecting the objectivity of this review.

\section{ACKNOWLEDGMENTS}

We are very grateful to Nick Davies, Mark Hauber, Keita Tanaka, Gerald Feeney, and Anastasia Dalziell for comments on the manuscript. We are also grateful to Rose Thorogood and Ros Gloag for helpful discussions. W.E.F. was supported by the Australian National University and Cambridge University. N.E.L. was supported by the Australian Research Council.

\section{LITERATURE CITED}

Alvarez F. 1999. Attractive non-mimetic stimuli in cuckoo Cuculus canorus eggs. Ibis 141:142-44

Anderson MG, Moskát C, Bán M, Grim T, Cassey P, Hauber ME. 2009a. Egg eviction imposes a recoverable cost of virulence in chicks of a brood parasite. PLOS ONE 4:e7725

Anderson MG, Ross HA, Brunton DH, Hauber ME. 2009b. Begging call matching between a specialist brood parasite and its host: a comparative approach to detect coevolution. Biol. 7. Linn. Soc. 98:208-16

Antonov A, Avilés JM, Stokke BG, Spasova V, Vikan JR, et al. 2011. Egg discrimination in an open nesting passerine under dim light conditions. Ethology 117:1128-37

Antonov A, Stokke BG, Fossøy F, Ranke PS, Liang W, et al. 2012. Are cuckoos maximizing egg mimicry by selecting host individuals with better matching egg phenotypes? PLOS ONE 7:e31704

Arcese P, Smith JN, Hatch MI. 1996. Nest predation by cowbirds and its consequences for passerine demography. Proc. Natl. Acad. Sci. USA 93:4608-11

Avilés JM, Vikan JR, Fossøy F, Antonov A, Moksnes A, et al. 2010. Avian colour perception predicts behavioural responses to experimental brood parasitism in chaffinches. F. Evol. Biol. 23:293-301

Bán M, Moskát C, Barta Z, Hauber ME. 2013. Simultaneous viewing of own and parasitic eggs is not required for egg rejection by a cuckoo host. Behav. Ecol. 24:1014-21

Birkhead TR, Hemmings N, Spottiswoode CN, Mikulica O, Moskát C, et al. 2011. Internal incubation and early hatching in brood parasitic birds. Proc. R. Soc. B-Biol. Sci. 278:1019-24

Briskie JV, Naugler CT, Leech SM. 1994. Begging intensity of nestling birds varies with sibling relatedness. Proc. R. Soc. B-Biol. Sci. 258:73-78 
Briskie JV, Sealy SG. 1990. Evolution of short incubation periods in the parasitic cowbirds, Molothrus spp. Auk 107:789-94

Britton N, Planqué R, Franks N. 2007. Evolution of defence portfolios in exploiter-victim systems. Bull. Math. Biol. 69:957-88

Brockhurst MA, Koskella B. 2013. Experimental coevolution of species interactions. Trends Ecol. Evol. 28:36775

Brooke M de L, Davies NB. 1988. Egg mimicry by cuckoos Cuculus canorus in relation to discrimination by hosts. Nature 335:630-32

Brooker MG, Brooker LC. 1989. Cuckoo hosts in Australia. Aust. Zool. Rev. 2:1-67

Brooker MG, Brooker LC. 1991. Eggshell strength in cuckoos and cowbirds. Ibis 133:406-13

Brown M, Lawes MJ. 2007. Colony size and nest density predict the likelihood of parasitism in the colonial southern red bishop Euplectes orix-Diderick cuckoo Chrysococcyx caprius system. Ibis 149:321-27

Campobello D, Sealy SG. 2011. Use of social over personal information enhances nest defense against avian brood parasitism. Behav. Ecol. 22:422-28

Canestrari D, Bolopo D, Turligs TCJ, Röder G, Marcos JM, Baglione V. 2014. From parasitism to mutualism: unexpected interactions between a cuckoo and its host. Science 343:1350-52

Canestrari D, Marcos JM, Baglione V. 2009. Cooperative breeding in carrion crows reduces the rate of brood parasitism by great spotted cuckoos. Anim. Behav. 77:1337-44

Cassey P, Honza M, Grim T, Hauber ME. 2008. The modelling of avian visual perception predicts behavioural rejection responses to foreign egg colours. Biol. Lett. 4:515-17

Cherry MI, Bennett ATD. 2001. Egg colour matching in an African cuckoo, as revealed by ultraviolet-visible reflectance spectrophotometry. Proc. R. Soc. B-Biol. Sci. 268:565-71

Cherry MI, Bennett ATD, Moskát C. 2007. Do cuckoos choose nests of great reed warblers on the basis of host egg appearance? F. Evol. Biol. 20:1218-22

Clark KL, Robertson RJ. 1979. Spatial and temporal multi-species nesting aggregations in birds as anti-parasite and anti-predator defenses. Behav. Ecol. Sociobiol. 5:359-71

Darwin C. 1859. On the Origin of Species. London: Murray

Davies NB. 2000. Cuckoos, Cowbirds and Other Cheats. London: T. \& A.D. Poyser

Davies NB. 2011. Cuckoo adaptations: trickery and tuning. F. Zool. 284:1-14

Davies NB, Brooke M de L. 1988. Cuckoos versus reed warblers: adaptations and counteradaptations. Anim. Behav. 36:262-84

Davies NB, Brooke M de L. 1989a. An experimental study of co-evolution between the cuckoo, Cuculus canorus, and its hosts. I. Host egg discrimination. 7. Anim. Ecol. 58:207-24

Davies NB, Brooke M de L. 1989b. An experimental study of co-evolution between the cuckoo, Cuculus canorus, and its hosts. II. Host egg markings, chick discrimination and general discussion. 7. Anim. Ecol. $58: 225-36$

Davies NB, Butchart SHM, Burke TA, Chaline N, Stewart IRK. 2003. Reed warblers guard against cuckoos and cuckoldry. Anim. Behav. 65:285-95

Davies NB, Welbergen JA. 2008. Cuckoo-hawk mimicry? An experimental test. Proc. R. Soc. B-Biol. Sci. 275:1817-22

Davies NB, Welbergen JA. 2009. Social transmission of a host defense against cuckoo parasitism. Science 324:1318-20

De Mársico MC, Gantchoff MG, Reboreda JC. 2012. Host-parasite coevolution beyond the nestling stage? Mimicry of host fledglings by the specialist screaming cowbird. Proc. R. Soc. B-Biol. Sci. 279:3401-8

De Mársico MC, Gloag R, Ursino CA, Reboreda JC. 2013. A novel method of rejection of brood parasitic eggs reduces parasitism intensity in a cowbird host. Biol. Lett. 9:20130076

Edvardsen E, Moksnes A, Røskaft E, Øien IJ, Honza M. 2001. Egg mimicry in cuckoos parasitizing four sympatric species of Acrocephalus warblers. Condor 103:829-37

Feeney WE, Langmore NE. 2013. Social learning of a brood parasite by its host. Biol. Lett. 9:20130443

Feeney WE, Medina I, Somveille M, Heinsohn R, Hall ML, et al. 2013. Brood parasitism and the evolution of cooperative breeding in birds. Science 342:1506-8

Feeney WE, Stoddard MC, Kilner RM, Langmore NE. 2014. "Jack-of-all-trades" egg mimicry in the brood parasitic Horsfield's bronze-cuckoo? Behav. Ecol. In press. doi: 10.1093/beheco/aru133 
Feeney WE, Welbergen JA, Langmore NE. 2012. The frontline of avian brood parasite-host coevolution. Anim. Behav. 84:3-12

Forsman JT, Martin TE. 2009. Habitat selection for parasite-free space by hosts of parasitic cowbirds. Oikos 118:464-70

Fossøy F, Antonov A, Moksnes A, Røskaft E, Vikan JR, et al. 2011. Genetic differentiation among sympatric cuckoo host races: Males matter. Proc. R. Soc. B-Biol. Sci. 278:1639-45

Geltsch N, Hauber ME, Anderson MG, Bán M, Moskát C. 2012. Competition with a host nestling for parental provisioning imposes recoverable costs on parasitic cuckoo chick's growth. Behav. Process. 90:378-83

Gibbs HL, Sorenson MD, Marchetti K, Brooke M de L, Davies NB, Nakamura H. 2000. Genetic evidence for female host-specific races in the common cuckoo. Nature 407:183-86

Gill SA, Sealy SG. 2004. Functional reference in an alarm signal given during nest defence: seet calls of yellow warblers denote brood-parasitic brown-headed cowbirds. Behav. Ecol. Sociobiol. 56:71-80

Gloag R, Fiorini VD, Reboreda JC, Kacelnik A. 2012. Brood parasite eggs enhance egg survivorship in a multiply parasitized host. Proc. R. Soc. B-Biol. Sci. 279:1831-39

Gloag R, Fiorini VD, Reboreda JC, Kacelnik A. 2013. The wages of violence: mobbing by mockingbirds as a frontline defence against brood-parasitic cowbirds. Anim. Behav. 86:1023-29

Gloag R, Keller L-A, Langmore NE. 2014. Cryptic cuckoo eggs hide from competing cuckoos. Proc. R. Soc. B-Biol. Sci. 281(1792):20141014

Gloag R, Tuero DT, Fiorini VD, Reboreda JC, Kacelnik A. 2011. The economics of nestmate killing in avian brood parasites: a provisions trade-off. Behav. Ecol. 23:132-40

Gluckman T-L, Mundy NI. 2013. Cuckoos in raptors' clothing: barred plumage illuminates a fundamental principle of Batesian mimicry. Anim. Behav. 86:1165-81

Grim T. 2007. Experimental evidence for chick discrimination without recognition in a brood parasite host. Proc. R. Soc. B-Biol. Sci. 274:373-81

Grim T. 2011. Ejecting chick cheats: a changing paradigm? Front. Zool. 8:14

Grim T, Samaš P, Moskát C, Kleven O, Honza M, et al. 2011. Constraints on host choice: Why do parasitic birds rarely exploit some common potential hosts? 7. Anim. Ecol. 80:508-18

Hamilton WJ III, Orians GH. 1965. Evolution of brood parasitism in altricial birds. Condor 67:361-82

Hauber ME. 2003a. Hatching asynchrony, nestling competition, and the cost of interspecific brood parasitism. Bebav. Ecol. 14:227-35

Hauber ME. 2003b. Interspecific brood parasitism and the evolution of host clutch sizes. Evol. Ecol. Res. 5:559-70

Hauber ME, Kilner RM. 2007. Coevolution, communication, and host-chick mimicry in parasitic finches: Who mimics whom? Behav. Ecol. Sociobiol. 61:497-503

Hett WS. 1936. Aristotle: Minor Works. On Marvellous Things Heard. London: Heinemann

Honza M, Procházka P, Stokke BG, Moksnes A, Røskaft E, et al. 2004. Are blackcaps current winners in the evolutionary struggle against the common cuckoo? F. Ethol. 22:175-80

Honza M, Šicha V, Procházka P, Ležalová R. 2006. Host nest defense against a color-dimorphic brood parasite: great reed warblers (Acrocephalus arundinaceus) versus common cuckoos (Cuculus canorus). 7. Ornithol. 147:629-37

Honza M, Taborsky B, Taborsky M, Teuschl Y, Vogl W, et al. 2002. Behaviour of female common cuckoos, Cuculus canorus, in the vicinity of host nests before and during egg laying: a radiotelemetry study. Anim. Behav. 64:861-68

Hoover JP, Robinson SK. 2007. Retaliatory mafia behavior by a parasitic cowbird favors host acceptance of parasitic eggs. Proc. Natl. Acad. Sci. USA 104:4479-83

Hoskin ES. 1989. A black-eared cuckoo and white-breasted woodswallows. Aust. Birds 2:35-36

Hosoi SA, Rothstein SI. 2000. Nest desertion and cowbird parasitism: evidence for evolved responses and evolutionary lag. Anim. Behav. 59:823-40

Kilner RM, Langmore NE. 2011. Cuckoos versus hosts in insects and birds: adaptations, counter-adaptations and outcomes. Biol. Rev. Camb. Pbilos. Soc. 86:836-52

Kilner RM, Madden JR, Hauber ME. 2004. Brood parasitic cowbird nestlings use host young to procure resources. Science 305:877-79 
Kilner RM, Noble DG, Davies NB. 1999. Signals of need in parent-offspring communication and their exploitation by the common cuckoo. Nature 397:667-72

Kleindorfer S, Evans C, Colombelli-Négrel D, Robertson J, Griggio M, Hoi H. 2013. Host response to cuckoo song is predicted by the future risk of brood parasitism. Front. Zool. 10:30

Krüger O. 2011. Brood parasitism selects for no defence in a cuckoo host. Proc. R. Soc. B-Biol. Sci. 278:2777-83

Krüger O, Davies NB. 2002. The evolution of cuckoo parasitism: a comparative analysis. Proc. R. Soc. B-Biol. Sci. 269:375-81

Krüger O, Davies NB, Sorenson MD. 2007. The evolution of sexual dimorphism in parasitic cuckoos: sexual selection or coevolution? Proc. R. Soc. B-Biol. Sci. 274:1553-60

Krüger O, Kolss M. 2013. Modelling the evolution of common cuckoo host-races: speciation or genetic swamping? 7. Evol. Biol. 26:2447-57

Krüger O, Sorenson MD, Davies NB. 2009. Does coevolution promote species richness in parasitic cuckoos? Proc. R. Soc. B-Biol. Sci. 276:3871-79

Lahti DC. 2005. Evolution of bird eggs in the absence of cuckoo parasitism. Proc. Natl. Acad. Sci. USA 102:18057-62

Lahti DC, Lahti AR. 2002. How precise is egg discrimination in weaverbirds? Anim. Behav. 63:1135-42

Langmore NE, Cockburn A, Russell AF, Kilner RM. 2009a. Flexible cuckoo chick-rejection rules in the superb fairy-wren. Behav. Ecol. 20:978-84

Langmore NE, Feeney WE, Crowe-Riddell J, Luan H, Louwrens KM, Cockburn A. 2012. Learned recognition of brood parasitic cuckoos in the superb fairy-wren Malurus cyaneus. Behav. Ecol. 23:798-805

Langmore NE, Hunt S, Kilner RM. 2003. Escalation of a coevolutionary arms race through host rejection of brood parasitic young. Nature 422:157-60

Langmore NE, Kilner RM, Butchart SHM, Maurer G, Davies NB, et al. 2005. The evolution of egg rejection by cuckoo hosts in Australia and Europe. Behav. Ecol. 16:868-92

Langmore NE, Maurer G, Adcock GJ, Kilner RM. 2008. Socially acquired host-specific mimicry and the evolution of host races in Horsfield's bronze-cuckoo Chalcites basalis. Evolution 62:1689-99

Langmore NE, Spottiswoode CN. 2012. Visual trickery in avian brood parasites. In Host Manipulation by Parasites, ed. DP Hughes, J Brodeur, F Thomas, pp. 95-118. Oxford, UK: Oxford Univ. Press

Langmore NE, Stevens M, Maurer G, Heinsohn R, Hall ML, et al. 2011. Visual mimicry of host nestlings by cuckoos. Proc. R. Soc. B-Biol. Sci. 278:2455-63

Langmore NE, Stevens M, Maurer G, Kilner RM. 2009b. Are dark cuckoo eggs cryptic in host nests? Anim. Behav. 78:461-68

Lotem A. 1993. Learning to recognize nestlings is maladaptive for cuckoo Cuculus canorus hosts. Nature 362:743-45

Lotem A, Nakamura H, Zahavi A. 1995. Constraints on egg discrimination and cuckoo-host co-evolution. Anim. Behav. 49:1185-209

Lyon BE, Eadie JM. 1991. Mode of development and interspecific avian brood parasitism. Behav. Ecol. 2:309-18

Lyon BE, Eadie JM. 2008. Conspecific brood parasitism in birds: a life-history perspective. Annu. Rev. Ecol. Evol. Syst. 39:343-63

Madden JR, Davies NB. 2006. A host-race difference in begging calls of nestling cuckoos Cuculus canorus develops through experience and increases host provisioning. Proc. R. Soc. B-Biol. Sci. 273:2343-51

Marchetti K. 2000. Egg rejection in a passerine bird: Size does matter. Anim. Behav. 59:877-83

Mason P, Rothstein SI. 1986. Coevolution and avian brood parasitism: Cowbird eggs show evolutionary response to host discrimination. Evolution 40:1207-14

Massoni V, Reboreda JC. 1999. Egg puncture allows shiny cowbirds to assess host egg development and suitability for parasitism. Proc. R. Soc. B-Biol. Sci. 266:1871-74

Mermoz ME, Ornelas JF. 2004. Phylogenetic analysis of life-history adaptations in parasitic cowbirds. Behav. Ecol. 15:109-19

Moksnes A, Røskaft E, Braa AT. 1991. Rejection behavior by common cuckoo hosts towards artificial brood parasite eggs. Auk 108:348-54

Møller AP, Saino N, Adamík P, Ambrosini R, Antonov A, et al. 2011. Rapid change in host use of the common cuckoo Cuculus canorus linked to climate change. Proc. R. Soc. B-Biol. Sci. 278:733-38 
Moskát C, Bán M, Szekely T, Komdeur J, Lucassen RWG, et al. 2010. Discordancy or template-based recognition? Dissecting the cognitive basis of the rejection of foreign eggs in hosts of avian brood parasites. 7. Exp. Biol. 213:1976-83

Nakamura H, Kubota S, Suzuki R. 1998. Coevolution between the common cuckoo and its major hosts in Japan: stable versus dynamic specialization on hosts. In Parasitic Birds and Their Hosts: Studies in Coevolution, ed. SI Rothstein, SK Robinson, pp. 94-112. New York: Oxford Univ. Press

Neudorf DL, Sealy SG. 1992. Reactions of four passerine species to threats of predation and cowbird parasitism: enemy recognition or generalized responses? Bebaviour 123:84-105

Pagnucco K, Zanette L, Clinchy M, Leonard ML. 2008. Sheep in wolf's clothing: Host nestling vocalizations resemble their cowbird competitor's. Proc. R. Soc. B-Biol. Sci. 275:1061-65

Patten M, Reinking D, Wolfe D. 2011. Hierarchical cues in brood parasite nest selection. F. Ornithol. 152:52132

Payne RB. 2005a. Nestling mouth markings and colors of old world finches Estrildidae: mimicry and coevolution of nesting finches and their Vidua brood parasites. Misc. Publ. Mus. Zool. Univ. Mich. 194:1-45

Payne RB. 2005b. The Cuckoos. Oxford, UK: Oxford Univ. Press

Polačiková L, Takasu F, Stokke B, Moksnes A, Røskaft E, et al. 2013. Egg arrangement in avian clutches covaries with the rejection of foreign eggs. Anim. Cogn. 16:819-28

Raj PJS. 1964. Communal breeding in the White-headed Babbler, Turdoides affinis (Jerdon) in Tambaram, Madras State. 7. Bombay Nat. Hist. Soc. 61:181-83

Remeŝ V. 2006. Growth strategies of passerine birds are related to brood parasitism by the brown-headed cowbird (Molothrus ater). Evolution 60:1692-700

Robert M, Sorci G. 2001. The evolution of obligate interspecific brood parasitism in birds. Behav. Ecol. 12:128-33

Rohwer S, Spaw C. 1988. Evolutionary lag versus bill-size constraints: a comparative study of the acceptance of cowbird eggs by old hosts. Evol. Ecol. 2:27-36

Rothstein SI. 1975. Mechanisms of avian egg-recognition: Do birds know their own eggs? Anim. Behav. 23:269-78

Rothstein SI. 1982. Mechanisms of avian egg recognition: Which egg parameters elicit responses by rejecter species? Behav. Ecol. Sociobiol. 11:229-39

Rothstein SI. 1990. A model system for coevolution: avian brood parasitism. Annu. Rev. Ecol. Syst. 21:481-508

Sato NJ, Mikamf OK, Ueda K. 2010a. The egg dilution effect hypothesis: a condition under which parasitic nestling ejection behaviour will evolve. Ornithol. Sci. 9:115-21

Sato NJ, Tokue K, Noske RA, Mikami OK, Ueda K. 2010b. Evicting cuckoo nestlings from the nest: a new anti-parasitism behaviour. Biol. Lett. 6:67-69

Shaw RC, Feeney WE, Hauber ME. 2014. Nest destruction elicits indiscriminate con- versus heterospecific brood parasitism in a captive bird. Ecol. Evol. In press

Shaw RC, Hauber ME. 2009. Experimental support for the role of nest predation in the evolution of brood parasitism. F. Evol. Biol. 22:1354-58

Smith JNM, Arcese P, McLean IG. 1984. Age, experience, and enemy recognition by wild song sparrows. Behav. Ecol. Sociobiol. 14:101-6

Soler JJ, Martín-Gálvez D, Martínez JG, Soler M, Canestrari D, et al. 2011. Evolution of tolerance by magpies to brood parasitism by great spotted cuckoos. Proc. R. Soc. B-Biol. Sci. 278:2047-52

Soler JJ, Martínez JG, Soler M, Møller AP. 1999. Host sexual selection and cuckoo parasitism: an analysis of nest size in sympatric and allopatric magpie Pica pica populations parasitized by the great spotted cuckoo Clamator glandarius. Proc. R. Soc. B-Biol. Sci. 266:1765-71

Soler JJ, Pérez-Contreras T, De Neve L, Macías-Sánchez E, Møller AP, Soler M. 2014. Recognizing odd smells and ejection of brood parasitic eggs. An experimental test in magpies of a novel defensive trait against brood parasitism. 7. Evol. Biol. 27:1265-70

Soler JJ, Soler M. 2000. Brood-parasite interactions between great spotted cuckoos and magpies: a model system for studying coevolutionary relationships. Oecologia 125:309-20

Soler M. 2011. Could egg rejection behaviour be transmitted by social learning? Anim. Behav. 81:e1-6

Soler M. 2014. Long-term coevolution between avian brood parasites and their hosts. Biol. Rev. Camb. Philos. Soc. 89:688-704 
Soler M, Soler JJ. 1991. Growth and development of great spotted cuckoos and their magpie host. Condor 93:49-54

Soler M, Soler JJ, Martínez JG, Møller AP. 1995. Magpie host manipulation by great spotted cuckoos: evidence for an avian mafia? Evolution 49:770-75

Sorenson MD, Balakrishnan CN, Payne RB. 2004. Clade-limited colonization in brood parasitic finches (Vidua spp.). Syst. Biol. 53:140-53

Sorenson MD, Payne RB. 2002. Molecular genetic perspectives on avian brood parasitism. Integr. Comp. Biol. 42:388-400

Sorenson MD, Sefc KM, Payne RB. 2003. Speciation by host switch in brood parasitic indigobirds. Nature 424:928-31

Spottiswoode CN. 2013. A brood parasite selects for its own egg traits. Biol. Lett. 9:20130573

Spottiswoode CN, Colebrook-Robjent JFR. 2007. Egg puncturing by the brood parasitic Greater Honeyguide and potential host counteradaptations. Behav. Ecol. 18:792-99

Spottiswoode CN, Koorevaar J. 2011. A stab in the dark: chick killing by brood parasitic honeyguides. Biol. Lett. 8:241-44

Spottiswoode CN, Stevens M. 2010. Visual modeling shows that avian host parents use multiple visual cues in rejecting parasitic eggs. Proc. Natl. Acad. Sci. USA 107:8672-76

Spottiswoode CN, Stevens M. 2011. How to evade a coevolving brood parasite: egg discrimination versus egg variability as host defences. Proc. R. Soc. B-Biol. Sci. 278:3566-73

Spottiswoode CN, Stevens M. 2012. Host-parasite arms races and rapid changes in bird egg appearance. $A m$. Nat. 179:633-48

Spottiswoode CN, Stryjewski KF, Quader S, Colebrook-Robjent JFR, Sorenson MD. 2011. Ancient host specificity within a single species of brood parasitic bird. Proc. Natl. Acad. Sci. USA 108:17738-42

Starling M, Heinsohn R, Cockburn A, Langmore NE. 2006. Cryptic gentes revealed in pallid cuckoos Cuculus pallidus using reflectance spectrophotometry. Proc. R. Soc. B-Biol. Sci. 273:1929-34

Stevens M, Troscianko J, Spottiswoode CN. 2013. Repeated targeting of the same hosts by a brood parasite compromises host egg rejection. Nat. Commun. 4:2475

Stoddard MC, Kilner RM, Town C. 2014. Pattern recognition algorithm reveals how birds evolve individual egg pattern signatures. Nat. Commun. 5:4117

Stoddard MC, Stevens M. 2010. Pattern mimicry of host eggs by the common cuckoo, as seen through a bird's eye. Proc. R. Soc. B-Biol. Sci. 277:1387-93

Stoddard MC, Stevens M. 2011. Avian vision and the evolution of egg color mimicry in the common cuckoo. Evolution 65:2004-13

Stokke BG, Moksnes A, Røskaft E. 2002. Obligate brood parasites as selective agents for evolution of egg appearance in passerine birds. Evolution 56:199-205

Stokke BG, Moksnes A, Røskaft E, Rudolfsen S, Honza M. 1999. Rejection of artificial cuckoo (Cuculus canorus) eggs in relation to variation in egg appearance among reed warblers (Acrocephalus scirpaceus). Proc. R. Soc. B-Biol. Sci. 266:1483-88

Tanaka KD, Morimoto G, Stevens M, Ueda K. 2011. Rethinking visual supernormal stimuli in cuckoos: visual modeling of host and parasite signals. Behav. Ecol. 22:1012-19

Tanaka KD, Ueda K. 2005. Horsfield's hawk-cuckoo nestlings simulate multiple gapes for begging. Science 308:653

Thompson JN. 1994. The Coevolutionary Process. Chicago: Univ. Chicago Press

Thorogood R, Davies NB. 2012. Cuckoos combat socially transmitted defenses of reed warbler hosts with a plumage polymorphism. Science 337:578-80

Thorogood R, Davies NB. 2013a. Hawk mimicry and the evolution of polymorphic cuckoos. Chin. Birds 4:39-50

Thorogood R, Davies NB. 2013b. Reed warbler hosts fine-tune their defenses to track three decades of cuckoo decline. Evolution 67:3545-55

Tokue K, Ueda K. 2010. Mangrove gerygones Gerygone laevigaster eject little bronze-cuckoo Chalcites minutillus hatchlings from parasitized nests. Ibis 152:835-39

Trnka A, Grim T. 2013. Color plumage polymorphism and predator mimicry in brood parasites. Front. Zool. 10:25 
Trnka A, Prokop P. 2012. The effectiveness of hawk mimicry in protecting cuckoos from aggressive hosts. Anim. Behav. 83:263-68

Trnka A, Prokop P, Grim T. 2012. Uncovering dangerous cheats: How do avian hosts recognize adult brood parasites? PLOS ONE 7:e37445

Underwood TJ, Sealy SG. 2006. Grasp-ejection in two small ejecters of cowbird eggs: a test of bill-size constraints and the evolutionary equilibrium hypothesis. Anim. Behav. 71:409-16

Welbergen J, Komdeur J, Kats R, Berg M. 2001. Egg discrimination in the Australian reed warbler (Acrocephalus australis): rejection response toward model and conspecific eggs depending on timing and mode of artificial parasitism. Behav. Ecol. 12:8-15

Welbergen JA, Davies NB. 2008. Reed warblers discriminate cuckoos from sparrowhawks with graded alarm signals that attract mates and neighbours. Anim. Behav. 76:811-22

Welbergen JA, Davies NB. 2009. Strategic variation in mobbing as a front line of defense against brood parasitism. Curr. Biol. 19:235-40

Welbergen JA, Davies NB. 2011. A parasite in wolf's clothing: Hawk mimicry reduces mobbing of cuckoos by hosts. Behav. Ecol. 22:574-79

Welbergen JA, Davies NB. 2012. Direct and indirect assessment of parasitism risk by a cuckoo host. Behav. Ecol. 23:783-89

Yom-Tov Y. 2001. An updated list and some comments on the occurrence of intraspecific nest parasitism in birds. Ibis 143:133-43

Yom-Tov Y, Geffen E. 2006. On the origin of brood parasitism in altricial birds. Behav. Ecol. 17:196-205

Zahavi A. 1979. Parasitism and nest predation in parasitic cuckoos. Am. Nat. 113:157-59 


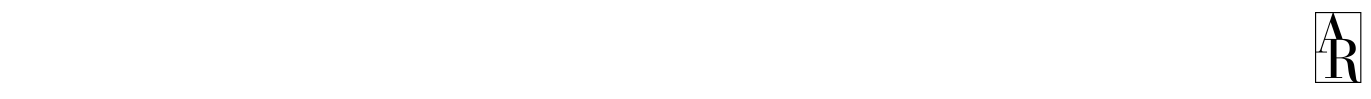

\section{Contents}

Annual Review of

Ecology, Evolution, and Systematics

Volume 45, 2014

Prescriptive Evolution to Conserve and Manage Biodiversity

Thomas B. Smith, Michael T. Kinnison, Sharon Y. Strauss,

Trevon L. Fuller, and Scott P. Carroll ......................................... 1

The Phylogeny and Evolution of Ants

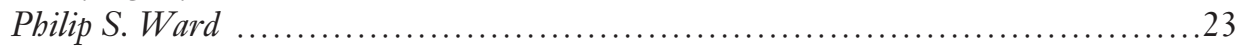

What Are Species Pools and When Are They Important?

Howard V. Cornell and Susan P. Harrison ....................................... 45

Biogeomorphic Impacts of Invasive Species

Songlin Fei, Jonathan Phillips, and Michael Shouse

Mutualistic Interactions and Biological Invasions

Anna Traveset and David M. Richardson

The Evolution of Animal Domestication

Greger Larson and Dorian Q. Fuller

Complex Ecological Interactions in the Coffee Agroecosystem

Ivette Perfecto, Fohn Vandermeer, and Stacy M. Philpott

Reversible Trait Loss: The Genetic Architecture of Female Ornaments

Ken Kraaijeveld.....

The Utility of Fisher's Geometric Model in Evolutionary Genetics

O. Tenaillon

The Molecular Basis of Phenotypic Convergence

Erica Bree Rosenblum, Cbristine E. Parent, and Erin E. Brandt

Advances in the Study of Coevolution Between Avian Brood Parasites and

Their Hosts

William E. Feeney, Fustin A. Welbergen, and Naomi E. Langmore

Ecological Restoration of Streams and Rivers: Shifting Strategies and Shifting Goals

Margaret A. Palmer, Kelly L. Hondula, and Benjamin 7. Koch 
Warmer Shorter Winters Disrupt Arctic Terrestrial Ecosystems

Elisabeth 7. Cooper

Unifying Species Diversity, Phylogenetic Diversity, Functional Diversity, and Related Similarity and Differentiation Measures Through Hill Numbers Anne Chao, Chun-Huo Chiu, and Lou fost

Trophic Cascades in a Multicausal World: Isle Royale and Yellowstone Rolf O. Peterson, Fohn A. Vucetich, Foseph M. Bump, and Douglas W. Smith 325

Origins of Plant Diversity in the California Floristic Province Bruce G. Baldwin

Animal Phylogeny and Its Evolutionary Implications Casey W. Dunn, Gonzalo Giribet, Gregory D. Edgecombe, and Andreas Hejnol

A Multiscale, Hierachical Model of Pulse Dynamics in Arid-Land Ecosystems

S.L. Collins, 7. Belnap, N.B. Grimm, 7.A. Rudgers, C.N. Dabm, P. D'Odorico, M. Litvak, D.O. Natvig, D.C. Peters, W.T. Pockman, R.L. Sinsabaugh, and B.O. Wolf .

Population Biology of Aging in the Wild

Deborah A. Roach and Fames R. Carey

Gecko Adhesion as a Model System for Integrative Biology, Interdisciplinary Science, and Bioinspired Engineering Kellar Autumn, Peter H. Niewiarowski, and Jonathan B. Puthoff 445

Biodiversity and Ecosystem Functioning

David Tilman, Forest Isbell, and Fane M. Cowles...

On the Nature and Evolutionary Impact of Phenotypic Robustness

Mechanisms

Mark L. Siegal and Fun-Yi Leu

Ecology and Evolution of the African Great Lakes and Their Faunas

Walter Salzburger, Bert Van Bocxlaer, and Andrew S. Cohen

Biome Shifts and Niche Evolution in Plants

Michael 7. Donoghue and Erika 7. Edwards...

Using Ancient DNA to Understand Evolutionary and Ecological Processes

Ludovic Orlando and Alan Cooper

Resolving Conflicts During the Evolutionary Transition to Multicellular Life

Paul B. Rainey and Silvia De Monte...

Speciation in Freshwater Fishes

Ole Seehausen and Catherine E. Wagner 


\section{New From Annual Reviews:}

\section{Annual Review of Statistics and Its Application}

Volume 1 • Online January $2014 \bullet$ http://statistics.annualreviews.org

\section{Editor: Stephen E. Fienberg, Carnegie Mellon University}

Associate Editors: Nancy Reid, University of Toronto

Stephen M. Stigler, University of Chicago

The Annual Review of Statistics and Its Application aims to inform statisticians and quantitative methodologists, as well as all scientists and users of statistics about major methodological advances and the computational tools that allow for their implementation. It will include developments in the field of statistics, including theoretical statistical underpinnings of new methodology, as well as developments in specific application domains such as biostatistics and bioinformatics, economics, machine learning, psychology, sociology, and aspects of the physical sciences.

\section{Complimentary online access to the first volume will be available until January 2015.}

TABLE OF CONTENTS:

- What Is Statistics? Stephen E. Fienberg

- A Systematic Statistical Approach to Evaluating Evidence from Observational Studies, David Madigan, Paul E. Stang, Jesse A. Berlin, Martijn Schuemie, J. Marc Overhage, Marc A. Suchard, Bill Dumouchel, Abraham G. Hartzema, Patrick B. Ryan

- The Role of Statistics in the Discovery of a Higgs Boson, David A. van Dyk

- Brain Imaging Analysis, F. DuBois Bowman

- Statistics and Climate, Peter Guttorp

- Climate Simulators and Climate Projections, Jonathan Rougier, Michael Goldstein

- Probabilistic Forecasting, Tilmann Gneiting, Matthias Katzfuss

- Bayesian Computational Tools, Christian P. Robert

- Bayesian Computation Via Markov Chain Monte Carlo, Radu V. Craiu, Jeffrey S. Rosenthal

- Build, Compute, Critique, Repeat: Data Analysis with Latent Variable Models, David M. Blei

- Structured Regularizers for High-Dimensional Problems: Statistical and Computational Issues, Martin J. Wainwright
- High-Dimensional Statistics with a View Toward Applications in Biology, Peter Bühlmann, Markus Kalisch, Lukas Meier

- Next-Generation Statistical Genetics: Modeling, Penalization, and Optimization in High-Dimensional Data, Kenneth Lange, Jeanette C. Papp, Janet S. Sinsheimer, Eric M. Sobel

- Breaking Bad: Two Decades of Life-Course Data Analysis in Criminology, Developmental Psychology, and Beyond, Elena A. Erosheva, Ross L. Matsueda, Donatello Telesca

- Event History Analysis, Niels Keiding

- Statistical Evaluation of Forensic DNA Profile Evidence, Christopher D. Steele, David J. Balding

- Using League Table Rankings in Public Policy Formation: Statistical Issues, Harvey Goldstein

- Statistical Ecology, Ruth King

- Estimating the Number of Species in Microbial Diversity Studies, John Bunge, Amy Willis, Fiona Walsh

- Dynamic Treatment Regimes, Bibhas Chakraborty, Susan A. Murphy

- Statistics and Related Topics in Single-Molecule Biophysics, Hong Qian, S.C. Kou

- Statistics and Quantitative Risk Management for Banking and Insurance, Paul Embrechts, Marius Hofert

Access this and all other Annual Reviews journals via your institution at www.annualreviews.org.
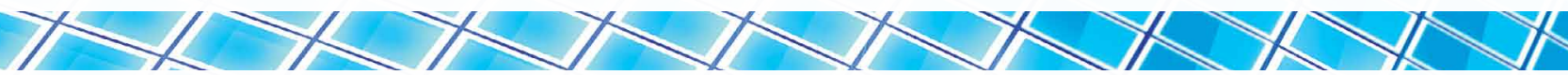

\section{ANNUAL REVIEWS | Connect With Our Experts}

Tel: 800.523.8635 (US/CAN) | Tel: 650.493.4400 | Fax: 650.424.0910 | Email: service@annualreviews.org 